\title{
1 Ferrocenyl Chalcone Derivatives as Possible Antimicrobial Agents
}

2 Elecia J Henry ${ }^{1 \mathrm{a}}$, Susan J Bird ${ }^{1 \mathrm{a}}$, Pauline Gowland ${ }^{1 \mathrm{a}}$ Michael Collins $^{2}$ and John P

3 Cassella $^{1 \mathrm{~b}}$

$4 \quad{ }^{1 a}$ School of Life Sciences and Education, Staffordshire University, Stoke-on-Trent, Staffordshire, ST4

$52 D F$, United Kingdom

$6{ }^{1 b}$ School of Law, Policing and Forensics, Staffordshire University, Stoke-on-Trent, Staffordshire, ST4

$7 \quad 2 D F$, United Kingdom

$8{ }^{2}$ Chesterfield Royal Hospital NHS Foundation Trust, Chesterfield Road, Calow, Chesterfield,

9 Derbyshire, S44 5BL, United Kingdom

11 Corresponding author name and address: Elecia J Henry, School of Life Sciences and Education,

12 Staffordshire University, Stoke-on-Trent, Staffordshire, ST4 2DF, United Kingdom.

13 Email address: elecia.henry@research.staffs.ac.uk; Elecia.Henry@sta.uwi.edu

15 Conflict of interest statement: No financial interest or benefit has arisen from the direct applications of this research.

17

${ }^{1}$ Present address of corresponding author.

${ }^{1}$ Department of Food Production, Frank Stockdale Building, University of the West Indies, St. Augustine, Trinidad \& Tobago, West Indies. 


\section{Abstract}

22 The swift spread of infections caused by drug-resistant bacteria, such as methicillin-resistant 23 Staphylococcus aureus (MRSA), has quickly become a worldwide concern as infections spread 24 from healthcare settings to the wider community. While ferrocenyl chalcones, which are 25 chalcone derivatives with antimicrobial activity, have gained attention from researchers, 26 further study is needed to assess their cytotoxicity. Ten newly developed chalcones, in which 27 ring A was replaced with a ferrocenyl moiety and ring B contained increasing alkyl chain 28 lengths from 5-10 carbons, were assessed. Using 2-fold broth microdilution, the minimum 29 inhibitory concentration (MIC) of five of the ten compounds were lower against Gram-positive 30 organisms (MICs from $0.008 \mathrm{mg} / \mathrm{ml}$ to $0.063 \mathrm{mg} / \mathrm{ml}$ ) than Gram-negative organisms (MICs = $310.125 \mathrm{mg} / \mathrm{ml}$ ). These novel ferrocenyl chalcone compounds were effective against 3 types of clinically isolated drug-resistant $S$. aureus, including a MRSA, and against other non-resistant clinically isolated and laboratory-adapted Gram-positive bacteria. The same compounds inhibited growth in non-resistant bacteria by potentially obstructing cellular respiration in Gram-positive bacteria. Images obtained through scanning electron microscopy revealed fully lysed bacterial cells once exposed to a selected compound that showed activity. The results indicate that these newly developed compounds could be important antimicrobial agents in the treatment of infections from clinically resistant bacteria. 
50

51

52

53

54

55

56

57

58

59

60

61

62

63

64

65

66

67

68

69

70

71

72

73

74

75

76

77

78

79

80

81

82

83

84

85

86

87

88

The increasing resistance of microorganisms to antibacterial agents is a global threat to public health and the over-prescription and misuse of antibacterial drugs have been identified as key factors in the development of bacterial antibiotic resistance [1]. In 2019, the World Health Organisation (WHO) published a working paper, which outlined the implementation and coordination of six strategies for a successful approach towards combatting antimicrobial resistance [2].

Resistance in bacteria can be influenced by the minimum inhibitory concentration (MIC) of a particular antibiotic at lethal or, more often, at sub-lethal levels. Bacteria that select for resistance because of sub-lethal antibiotic levels may use various mechanisms of drug resistance including mutations in bacterial genes responsible for antimicrobial susceptibility, which may be integrated or transferable [3], or mutations in efflux pumps in bacterial cells [4]. Lack of bioavailability leading to low blood and tissue levels can lead to suboptimal drug exposure leading to microbes becoming resistant. Raising dose levels could lead to enhanced toxicity and adverse events [5], [6].

The initial focus of the prevalence of antimicrobial drug resistance was limited to nosocomial infections caused by methicillin-resistant Staphylococcus aureus (MRSA) and glycopeptide-resistant Enterococci (GRE) but similar infections began to emerge in the community and in non-clinical environments [7]. Subsequently, the WHO [8] reported the existence of other multidrug-resistant (MDR) bacteria including carbapenemase-producing Enterobacteriaceae (CPE), the most common being Klebsiella pneumoniae and Escherichia coli [9]. A report by Allegranzi et al. [10] indicated that MDR-associated nosocomial infections in developing countries (15.5 per 100 patients) were higher than the mean incidence in European health institutions (7.1 per 100 patients) because of unsafe surgeries that may include surgical instruments contaminated with resistant bacteria. This increased risk suggests the need for greater scrutiny of surgical procedures and related infection control practices.

The emergence of CPEs has prompted an increase in the use of colistin (polymixin E), which is considered to be the 'last line of defence' and is a critical agent against some common multidrugresistant Gram-negative aerobic bacilli, including CPEs. The mechanism of action of colistin is to damage the integrity of the outer envelope of Gram-negative bacilli by causing instability of membrane-bound lipopolysaccharides (LPS) [11]. This damage allows cellular contents to escape, resulting in apoptosis but the toxic effects of colistin on the human kidney prevented its use in routine antimicrobial therapy [12]. Overuse of colistin has now resulted in infections caused by colistin-resistant CPEs. Initially, resistance was thought to result from chromosomal mutations but recent reports have shown that resistance can be mediated by the transfer of plasmids containing the colistin-resistant gene known as MCR-1 [13]. A 2016 report by the European Centre for Disease Prevention and Control (ECDC) described infections caused by this type of colistin resistance as a critical public health issue [14].

Even as resistance to available antibacterial agents increases, the number of new, effective agents being discovered particularly for Gram-negative infections remains small [15]. Poor financial returns of approved antibiotics, combined with a reduction of regulatory approval for new drugs to treat drug-resistant bacteria, has affected progress in the development of new antibiotics [16], [17]. A 
clear need exists for development of novel antibacterial drugs with increased efficacy, particularly against infections caused by MDR Gram-negative organisms [18].

\section{Chalcones}

One avenue of research into antimicrobial drug development is the use of flavonoids [19]. These organic compounds, synthesised by plants, contribute to the colour in flowers making them alluring to pollinators, increase survival by protecting them from fungal infection and ultra violet radiation, and are involved in essential cellular processes such as energy transfer, respiration and photosynthesis [19]. Another key role is as an antioxidant. Chalcones (Figure 3), a class of flavonoids, have attracted the attention of researchers as they show reduced cytotoxicity to humans and increased antibacterial potency [19]. Specifically, ferrocene-containing chalcones have been shown to be attractive potential antimicrobial agents due to their favourable characteristics such as lipophilicity and ease of chemical modification [20] suggesting that they may also be potential scaffold molecules for other new potent antimicrobial drugs [19], [21]-[24].

\section{Ferrocenyl chalcones}

Researchers are focussed on ferrocene-type drugs because of their benefits such as their small size, comparative lipophilicity, a key feature allowing diffusion across cell membranes, ease of chemical modification, as mentioned above, and accessible one-electron-oxidation potential. Classes of ferrocenyl chalcones are primarily of two types, as seen in Figure 1; Type 1 where the carbonyl group is at the $\alpha$-position adjacent to the ferrocenyl ring and Type 2 where the carbonyl group is at the $\alpha$ position adjacent to the phenyl ring.

However, these compounds require further study to determine their efficacy and any possible toxicity to mammalian cells [20].

Ferrocenyl chalcones have been altered to produce sulfones [25]. These sulphur-based compounds were synthesized using the meta-chloroperbenzoic acid, catalysed oxidation of ferrocenyl chalcone sulfides (Figure 2). Much like the ferrocenyl chalcone derivatives used in the current study, several of the compounds described by Ahmed et al. reportedly inhibited bacterial growth at minimum inhibitory concentrations (MIC) lower than amikacin and ampicillin [26].

The research described in this paper involved the testing of novel functionalised ferrocenyl chalcones (Chart 1). The overall synthesis of these Type 2 ferrocenyl chalcones, which were produced by Crouch [27], are shown in Figure 3.

The lipophilicity of these compounds increased as alkyl chain length of the R group increased (from methyl to decyl). In the current study, the antimicrobial activity of these highly lipophilic chemicals were investigated as well as their mode(s) of action, which possibly involved the reduction of bacterial cell viability.

The newly developed ferrocenyl chalcones used in this study will be investigated to determine if one potential mechanism was to block bacterial dehydrogenases involved in respiration, which would 
interrupt the bacterial electron transport chain necessary for energy and growth as described by Haddock \& Jones [28]. The current study used 3-(4,5-dimethylthiazol-2-yl)-2,5-diphenyltetrazolium bromide (MTT) to indicate bacterial cell viability in terms of the amount of formazan product formed [29]. In actively respiring cells, these respiratory dehydrogenases were considered to reduce the yellow MTT compound to insoluble purple formazan [30]. The MTT assay is an inexpensive method that has been used to demonstrate inhibition of bacterial cell respiration as an indicator of cell viability of Escherichia coli [31] and Mycobacterium tuberculosis H37Rv [29]. Inhibition of this vital cellular process can result in cellular lysis.

Scanning electron microscopy (SEM) was used to gain images to obtain an insight into possible external morphological changes to the cells. These changes could include visible pores on the envelope like that seen in antimicrobial peptide activity against E. coli 25922 and Staphylococcus aureus 25923 [32], or fully lysed cells like those seen in the treatment of Bacillus cereus with sucrose monocaprate [33].

\section{Aims and objectives}

The principle aim of this study was to identify any antimicrobial activity of the ferrocenyl chalcone derivatives on non-resistant laboratory-adapted bacteria, followed by identifying if there was also antimicrobial activity against a panel of drug-resistant and non-resistant clinical isolates from the Royal Chesterfield Hospital, UK. The organisms used in the current study were selected based on availability and to represent a broad spectrum of bacteria. The proposed method was based on the 2-fold broth microdilution method described by Andrews [34]. Another aim of the current study was to determine the potential mechanism of action of the ferrocenyl chalcone derivatives using MTT assay as described by Moodley et al. [29]. Finally, the project aimed to obtain micrographic evidence of possible external damage to bacterial cells that may result from exposure to these compounds using SEM as detailed by Hartmann et al. [32].

\section{Material and Methods}

\section{Preparation of ferrocenyl chalcones and control antibiotics}

Ferrocenyl chalcones of increasing alkyl chain lengths (methyl to decyl) were provided by Crouch [27]. Fresh stock solutions of each compound were prepared at $1 \mathrm{mg} / \mathrm{ml}$ in dimethyl sulfoxide (DMSO) (Alfa Aesar, Lancashire, UK) for each assay. Stock $250 \mathrm{mg} / \mathrm{ml}$ antibiotic solutions of penicillin-G (Sigma, Dorset, UK) and oxytetracycline were prepared in sterile deionised water according to the standard method described by Andrews [34]. Each solution was divided into $1 \mathrm{ml}$ aliquots in sterile microcentrifuge tubes and then stored at $-200 \mathrm{C}$.

\section{Preparation of inocula}

Inocula of S. aureus NCIMB 8244, E. faecalis NCTC 12697, K. kristinae NCIMB 8884, E. coli NCIMB 9483, K. pneumoniae (IH) and Salmonella serotype Manchester NCTC 7832 were prepared by 
suspending at least 3-4 colonies of each organism into individual sterile $10 \mathrm{ml}$ aliquots of sterile Oxoid MH broth (Fisher Scientific, Loughborough, UK) and incubated for $15-20$ minutes at $37^{\circ} \mathrm{C}$ in air while stirring. Suspensions were diluted 1:100 in sterile $\mathrm{MH}$ broth to gain starting inocula of $10^{5}$ per BSAC standards. Clinical isolates of non-resistant E. coli, S. aureus, resistant S. aureus (penicillin; erythromycin, penicillin, clindamycin) and a MRSA were prepared as described in the previous sentence. K. kristinae NCIMB 8884 were prepared 1:10 also per BSAC standards.

\section{Minimum inhibitory concentration assay}

Minimum inhibitory concentrations (MICs) were determined using 2-fold serial broth microdilution of each ferrocenyl chalcone compound with sterile $\mathrm{MH}$ broth. Each prepared inoculum (75 $\mu \mathrm{l}$ ) was added to equal volumes of diluted ferrocenyl chalcone solution in Nunc $0.2 \mathrm{ml}$ flat bottom 96-well 12-column microtitre plates (Fisher Scientific, Loughborough, UK). This was repeated for each ferrocenyl chalcone compound. Column 11 was treated with antibiotic (penicillin-G and oxytetracycline) and column 12 was left untreated. Plates were then incubated at $37^{\circ} \mathrm{C}$ for $18-24$ hours. Absorbance values were measured using a Rosys Anthos 2010 microplate reader (Salzberg, Austria) at $620 \mathrm{~nm}$ adapted from Medu [35].

\section{Bacterial MTT assay}

Bacterial cell viability of resistant and non-resistant bacteria at MIC was determined by inoculating 96-well microplates as described above, followed by the addition of $10 \mu \mathrm{l}$ of MTT solution $(5 \mathrm{mg} / \mathrm{ml})$ (Sigma-Aldrich, Dorset, UK). Plates were incubated at room temperature for 3 hours followed by addition of $50 \mu \mathrm{l}$ of DMSO. Absorbance values were measured at $570 \mathrm{~nm}$.

\section{Bacterial Scanning Electron Microscopy (SEM)}

Treated non-resistant bacteria, S. aureus NCIMB 8244, K. kristinae NCIMB 8884 and E. faecalis NCTC 12697 were exposed to decyl ferrocenyl chalcone solution at MIC value and incubated for 18-24 hours at $37^{\circ} \mathrm{C}$, whilst untreated cells were incubated under the same conditions in the absence of chalcone. Treated and untreated cells were incubated with $2 \%$ w/v glutaraldehyde for 1 hour then washed with sterile phosphate buffer saline (PBS) by centrifugation [32]. The cells were then dehydrated with a graded series of ethanol $(20 \% \mathrm{v} / \mathrm{v}, 40 \% \mathrm{v} / \mathrm{v}, 60 \% \mathrm{v} / \mathrm{v}, 80 \% \mathrm{v} / \mathrm{v}, 95 \% \mathrm{v} / \mathrm{v}, 100 \% \mathrm{v} / \mathrm{v}$, $100 \% \mathrm{v} / \mathrm{v}, 100 \% \mathrm{v} / \mathrm{v})$ and re-suspended in sterile deionised water. Re-suspended cells (10 $\mu \mathrm{l})$ were pipetted on to $0.2 \mu \mathrm{m}$ Cyclopore Track Etch polycarbonate membrane filter discs (Whatman International Limited, Maidstone, UK) and sputter-coated with gold. Secondary electron images were taken using the JEOL JSM 6610V SEM (Herts, UK).

\section{Statistical analysis}

The Kolmogorov-Smirnoff test was used to determine data normality of the MTT assay data. Statistical analysis of the MTT assay data in the study was performed using a One-Way ANOVA to determine if the mean percentage of actively respiring cells differed between the hexyl to decyl 
ferrocenyl chalcones treatments.

196

\section{Results}

\section{MIC assay}

Methyl to pentyl ferrocenyl chalcones showed lower antimicrobial activity than hexyl to decyl ferrocenyl chalcones (Table 1). The former group of compounds showed MIC values of $0.125 \mathrm{mg} / \mathrm{ml}$ ( \pm 0.000 ) for all organisms tested. MIC values at $0.125 \mathrm{mg} / \mathrm{ml}$ contained $12.5 \% \mathrm{v} / \mathrm{v}$ DMSO, which was the threshold at which microbial growth was seen. The chalcones with longer alkyl chain lengths (hexyl-decyl) also had lower MICs against Gram-positive bacteria than against Gram-negative bacteria. MIC of these compounds with longer alkyl chains ranged from $0.008 \mathrm{mg} / \mathrm{ml}( \pm 0.000)$ and $0.063 \mathrm{mg} / \mathrm{ml}( \pm 0.000)$ for S. aureus NCIMB 8244, E. faecalis NCTC 12697, K. kristinae NCIMB 8884 and a non-resistant clinical isolate of $S$. aureus, while MICs against all Gram-negatives $=0.125 \mathrm{mg} / \mathrm{ml}$ $( \pm 0.000)$. MICs for the same longer alkyl chain ferrocenyl chalcones against resistant clinical isolates range of $S$. aureus from $0.031 \mathrm{mg} / \mathrm{ml}( \pm 0.000)$ to $0.063 \mathrm{mg} / \mathrm{ml}( \pm 0.000)$. No growth was observed with organisms that were treated with penicillin-G or oxytetracycline at an MIC of $0.125 \mathrm{mg} / \mathrm{ml}$.

\section{MTT assay}

The results of the MTT assay of non-resistant Gram-positive laboratory organisms demonstrated that the percentage of actively respiring cells, in terms of formazan product observed (Figure 4) decreased after exposure to chalcones at the MIC value. No viable cells (mean estimated percentage of $0 \%$ ) were seen for S. aureus NCIMB 8244 when exposed to hexyl and octyl, for K. kristinae NCIMB 8884 after exposure to hexyl and heptyl, and for E. faecalis NCTC 12697 when exposed to hexyl and heptyl. The highest percentage was measured for S. aureus NCIMB 8244 after incubation with decyl (4.241\%).

In the MTT assay of resistant and non-resistant Gram-positive clinical isolates the percentage of actively respiring cells, in terms of formazan product observed (Figure 5) also decreased after exposure to chalcones at the MIC value. No viable cells (mean percentage of $0 \%$ ) were seen for fully sensitive S. aureus (RCH) when exposed to hexyl, heptyl and octyl, for PEN-resistant S. aureus (RCH) when exposed to heptyl, octyl, nonyl and decyl, for PEN/ERY/CLI-resistant S. aureus (RCH) and MRSA when exposed to hexyl, heptyl, nonyl and decyl. The highest percentage was determined for fully sensitive S. aureus (RCH) after incubation with nonyl (2.242\%).

There were no significant differences at $p=0.05$ between these chalcones (hexyl to decyl), in terms of mean percentage $( \pm S D)$ of actively respiring cells present, against $S$. aureus NCIMB $8244(p=0.107)$, K. kristinae NCIMB $8884(\mathrm{p}=0.326)$ and E. faecalis NCTC $12697(\mathrm{p}=0.118)$. Similarly, there were no significant differences between these compounds against fully sensitive $S$. aureus $(R C H)(p=0.523)$, penicillin-resistant S. aureus $(\mathrm{RCH})(\mathrm{p}=0.418), P E N-, E R Y-, C L I$-resistant $S$. aureus $(\mathrm{RCH})(\mathrm{p}=0.418)$ and a MRSA (RCH) $(\mathrm{p}=0.418)$. 
The SEM images (Figures 6A-F) revealed that exposure to decyl ferrocenyl chalcone resulted in morphological changes to bacterial cells at MIC. The affected cells appeared fully lysed, while unaffected cells maintained their spherical or spherical-like (opioid) appearance.

\section{Discussion}

In the broth microdilution assay, fresh DMSO was used as the solvent for the ferrocenyl chalcones. The results showed that MIC values of the methyl to pentyl ferrocenyl chalcone compounds $(0.125$ $\mathrm{mg} / \mathrm{ml}$ in $12.5 \% \mathrm{v} / \mathrm{v}$ DMSO ) were within the reported values for penicillin $(0.000015-0.128 \mathrm{mg} / \mathrm{ml})$ against Staphylococci [34]. In the same assay, the MIC values of all 10 compounds were $0.125 \mathrm{mg} / \mathrm{ml}$ in $12.5 \% \%$ DMSO against Enterobacteriaceae, which were within the values reported by Andrews [34] for tetracycline $(0.00025-0.128 \mathrm{mg} / \mathrm{ml})$ against Enterobacteriaceae. These values were used since oxytetracycline is an analogue of tetracycline. However, growth inhibition may also have resulted from exposure of the organisms to DMSO. DMSO has been shown to have an inhibitory effect at percentages equal to and/or greater than $12.5 \% \mathrm{v} / \mathrm{v}$ [36]. This was confirmed in a simultaneous study but not reported in the current paper. The chalcone MIC values for S. aureus NCIMB 8244 began to decrease as alkyl chain length increased. This was especially seen with hexyl to nonyl $(0.063 \mathrm{mg} / \mathrm{ml})$ and decyl $(0.031 \mathrm{mg} / \mathrm{ml})$. Except for hexyl against clinically isolated S. aureus (fully sensitive) $(\mathrm{RCH})$, sensitivity was also seen for hexyl to decyl against penicillin-resistant $\mathrm{S}$. aureus $(\mathrm{RCH})$, penicillin-, erythromycin-, clindamycin-resistant $\mathrm{S}$. aureus clinical isolates (RCH) $(0.031 \mathrm{mg} / \mathrm{ml}$ to $0.063 \mathrm{mg} / \mathrm{ml}$ ). No growth was observed with organisms that were treated with approximately $0.125 \mathrm{mg} / \mathrm{ml}$ of known control antibiotics, which were within the reported MIC range of penicillin and tetracycline [34].

The MIC values reported in Table 1 varied between each organism and between each chalcone. When used against $S$. pyogenes NCIMB 8884, which was later confirmed to be $K$. kristinae, all chalcones with longer alkyl chains showed MIC values of $0.016 \mathrm{mg} / \mathrm{ml}$ except for hexyl $(0.031$ $\mathrm{mg} / \mathrm{ml}$ ) and heptyl $(0.008 \mathrm{mg} / \mathrm{ml})$. When used against E. faecalis NCTC 12697, hexyl to decyl ferrocenyl chalcones showed MIC values of $0.063 \mathrm{mg} / \mathrm{ml}$. These values were also within the expected range (0.0005-0.128 mg/ml) for Enterococci [34]. Although antimicrobial activity was seen with hexyl to decyl against K. pneumoniae (IH), E. coli (RCH), E. coli NCIMB 9483 and Salmonella "Manchester" NCTC $7372(0.125 \mathrm{mg} / \mathrm{ml})$, it may have resulted from sensitivity to $12.5 \% \mathrm{v} / \mathrm{v}$ DMSO.

The overall trend appeared to be that the chalcones had a greater inhibitory effect on Gram-positive bacteria than on Gram-negative bacteria. The difference in MIC values with respect to the Gramnegative and Gram-positive organisms may be because of increasing alkyl chain length. One explanation why the Gram reaction may have been a factor was that the compounds may have passed across the thick hydrophilic peptidoglycan layer of Gram-positive bacteria because of the amphipathic DMSO [37]. The long chains may have become trapped in the cell membrane allowing the attached ferrocenyl groups, which were relatively smaller than the alkyl chains, to enter the cytoplasm. Since Gram-negative bacteria have outer envelopes with membrane transporter proteins such as porins, followed by thin peptidoglycan layers and cell membranes in their cellular envelopes, 
entry into these cells may have been more difficult. These porins would have allowed hydrophilic compounds to enter, while hydrophobic compounds may have diffused across the lipid bilayer of the outer envelope [38]. However, because of the fluidity of the outer lipid bilayer of Gram-negative bacteria, the long alkyl chains of the ferrocenyl chalcones may have become trapped in the outer envelope and would have been unable to cross the peptidoglycan layer and cell membrane into the cells. Another reason why the difference between Gram-negative and Gram-positive bacteria may have been important was that organisms such as $E$. coli had become used to living in enriched media, which promoted vigorous growth [39].

The MIC values of the ferrocenyl chalcones against the organisms used in this study corresponded with the percentage of actively respiring cells in terms of the formazan product seen. This suggests that the metabolic process used to convert MTT, as discussed by Riss et al. [30], was not active at the concentrations of chalcones present in the cells. Therefore, little or no formazan product was detected at $570 \mathrm{~nm}$ on the microplate reader. In the MTT assay involving Gram-negative bacteria, growth inhibition, which was seen at $0.125 \mathrm{mg} / \mathrm{ml}$, may also have resulted from exposure of the organisms to DMSO. This implies that the percentage of viable cells that were involved in MTT metabolism to formazan were very low at the assessed MIC.

When compared to MTT screening of ferrocenyl chalcone antimicrobial activity against Mycobacterium tuberculosis, the MIC values in this study lay within the reported range (0.016-0.128 $\mathrm{mg} / \mathrm{ml}$ ) [29], except for K. kristinae where a lower MIC (heptyl chalcone) was used. In the microplate assays, the overall trend showed that the chalcones had a greater inhibitory effect on Grampositives than on Gram-negatives. The trend also indicated that there were no significant differences between the chalcones with longer alkyl chains (hexyl to decyl) in terms of mean percentage ( $\pm S D$ ) of actively respiring cells present against S. aureus NCIMB 8244, K. kristinae NCIMB 8884 and E. faecalis NCTC 12697. Thus, the compounds were equally effective at inhibiting respiration in bacterial cells. Similarly, the chalcones were equally effective at respiration inhibition for fully sensitive $S$. aureus $(\mathrm{RCH})$, penicillin-resistant S. aureus (RCH), PEN-, ERY-, CLI-resistant S. aureus (RCH) and a MRSA $(\mathrm{RCH})$. Increased chain length may have allowed the ferrocene groups to enter the cytoplasm of Gram-positive organisms. Ferrocene groups have been proposed to be inhibitors of cellular respiration, in which the ferrocene groups act as uncouplers [20]. Since Gram-negative organisms possess outer envelopes, thin peptidoglycan layers with increased periplasmic space and cell membranes in their cell envelopes, entry into these cells may be more difficult. Another possibility was that the cell membrane of Gram-positive bacteria was compromised such that the electron transport chain cannot function [28]. Cell viability, as indicated by MTT metabolism to formazan, decreased in Gram-positives when compared to Gram-negatives. Therefore, a possible mechanism of action of the chalcones with longer alkyl chain lengths may have been inhibition of cellular respiration.

Visible effects of possible inhibition of cellular respiration were seen in micrographs of bacterial samples (Figures 6B, 6D \& 6F) at MIC, where the cells exhibited lysis when treated with decyl ferrocenyl chalcone. In contrast, untreated S. aureus NCIMB 8244, K. kristinae NCIMB 8884 and E. faecalis NCTC 12697 appeared unaffected externally (Figure 6A, 6C \& 6E). This potential mode of action was proposed based on observations of similar cellular damage caused by respiration 
inhibitors when S. aureus ATCC 25923 was exposed to graphene films on three types of conductors [40] and when S. aureus RSSK01009 were exposed to essential oil terpenes [41].

This spread is in part caused by the misuse of antibiotics and the unavailability of new drugs. This is the first report to demonstrate that ferrocenyl chalcones, which can be structurally altered by synthetic methods, possess significant antimicrobial activity against non-resistant lab organisms and resistant and non-resistant clinical isolates. This study also indicates that activity was potentially characterised by interference of bacterial respiration. The findings of this study reveal that these novel ferrocenyl chalcone compounds are potential antimicrobial agents against clinical bacterial isolates requiring further investigation.

In order to progress the possible use of ferrocenyl chalcones alkyl iodide chains as promising alternative antimicrobial drugs, future research into these current chemicals, which includes their effects against biofilms and mammalian cells. Further assays involving the efficacy of the compounds against biofilms, such as a comparable study reported by Kunthalert et al. [42], and cytotoxicity against mammalian cells, such as a similar study reported by Kowalski et al. [43] are needed to strengthen the profile of the ferrocenyl chalcone compounds.

\section{Acknowledgments}

This research did not receive any specific grant from funding agencies in the public, commercial, or not-for-profit sectors. The ferrocenyl chalcone compounds were provided by L. Crouch and R. Smith (University of Central Lancashire) and the clinical isolates were donated by M. Collins (Chesterfield Royal Hospital NHS Foundation Trust).

\section{References}

[1] Davies J, Davies D. Origins and Evolution of Antibiotic Resistance. Microbiol Mol Biol Rev. 2010;74(3):417-33.

[2] World Health Organisation. Turning Plans into Action for Antimicrobial Resistance (AMR) Working Paper 2.0: Implementation and Coordination. Geneva; 2019.

[3] Gullberg E, Cao S, Berg OG, Ilbäck C, Sandegren L, Hughes D, Andersson DI. Selection of resistant bacteria at very low antibiotic concentrations. PLoS Pathog. 2011;7(7):1-9.

[4] Edwards B, Andini R, Esposito S, Grossi P, Lew D, Mazzei T, Novelli a., Soriano a., Gould IM. Treatment options for methicillin-resistant Staphylococcus aureus (MRSA) infection: Where are we now? J Glob Antimicrob Resist. 2014 Sep;2(3):133-40.

[5] Normark S, Edlund T, Grundstrom T, Bergstrom S, Wolfwatz H. Escherichia coli K12 mutants hyper producing chromosomal beta lactamase by gene repetitions. J Bacteriol. 1977;132(3):912-22.

[6] Song S, Berg OG, Roth JR, Andersson DI. Contribution of gene amplification to evolution of increased antibiotic resistance in Salmonella typhimurium. Genetics. 2009;182(4):1183-95. 
[7] Hadley S. Resistant Gram-Positive Infections: Where Have We Been, Where Are We Now, and Where Are We Going? Clin Ther. 2014 Oct 3;36(10):1298-302.

[8] WHO. Worldwide Country Situation Analysis: Response to Antimicrobial Resistance. Geneva; 2015.

[9] Tseng S-H, Lee C-M, Lin T-Y, Chang S-C, Chang F-Y. Emergence and spread of multi-drug resistant organisms: think globally and act locally. J Microbiol Immunol Infect. 2011 Jun;44(3):157-65.

[10] Allegranzi B, Bagheri Nejad S, Combescure C, Graafmans W, Attar H, Donaldson L, Pittet D. Burden of endemic health-careassociated infection in developing countries: systematic review and meta-analysis. Lancet Infect Dis. 2011;377:228-41.

[11] Newton BA. The properties and mode of action of the polymixins. Bact Rev. 1956;20:14-27.

[12] Falagas ME, Kasiakou SK. Colistin: The Revival of Polymyxins for the Management of Multidrug-Resistant Gram-Negative Bacterial Infections. Clin Infect Dis. 2005;40:1333-41.

[13] Liu YY, Wang Y, Walsh TR, Yi LX, Zhang R, Spencer J, Doi Y, Tian G, Dong B, Huang X, Yu LF, Gu $D$, Ren H, Chen X, Lv L, He D, Zhou H, Liang Z, Liu JH, Shen J. Emergence of plasmid-mediated colistin resistance mechanism MCR-1 in animals and human beings in China: A microbiological and molecular biological study. Lancet Infect Dis. 2016;16:161-8.

[14] European Centre for Disease Prevention and Control (ECDC). Plasmid-mediated colistin resistance in Enterobacteriaceae. Stockholm; 2016.

[15] Oelschlaeger P, Ai N, Duprez KT, Welsh WJ, Toney JH. Evolving carbapenemases: can medicinal chemists advance one step ahead of the coming storm? J Med Chem. $2010 \mathrm{Apr}$ 22;53(8):3013-27.

[16] Spellberg B, Blaser M, Guidos RJ, Boucher HW, Bradley JS, Eisenstein BI, Gerding D, Lynfield R, Reller LB, Rex J, Schwartz D, Septimus E, Tenover FC, Gilbert DN. Combating antimicrobial resistance: Policy recommendations to save lives. Clin Infect Dis. 2011;52(SUPPL. 5):397-428.

[17] Kinch MS, Patridge E, Plummer M, Hoyer D. An analysis of FDA-approved drugs for infectious disease: antibacterial agents. Drug Discov Today. 2014 Sep;19(9):1283-7.

[18] Shlaes DM, Spellberg B. Overcoming the challenges to developing new antibiotics. Curr Opin Pharmacol. 2012 Oct;12(5):522-6.

[19] Cushnie TPT, Lamb AJ. Recent advances in understanding the antibacterial properties of flavonoids. Int J Antimicrob Agents. 2011 Aug;38(2):99-107.

[20] Attar S, O'Brien Z, Alhaddad H, Golden ML, Calderón-Urrea A. Ferrocenyl chalcones versus organic chalcones: a comparative study of their nematocidal activity. Bioorg Med Chem. 2011 Mar 15;19(6):2055-73.

[21] Pereira Ávila H, Smânia EDFA, Monache FD, Smânia A. Structure-activity relationship of 
antibacterial chalcones. Bioorganic Med Chem. 2008;16(22):9790-4.

[22] Moreira Osório T, Delle Monache F, Domeneghini Chiaradia L, Mascarello A, Regina Stumpf T, Roberto Zanetti C, Bardini Silveira D, Regina Monte Barardi C, de Fatima Albino Smânia E, Viancelli A, Ariel Totaro Garcia L, Augusto Yunes R, José Nunes R, Smânia A. Antibacterial activity of chalcones, hydrazones and oxadiazoles against methicillin-resistant Staphylococcus aureus. Bioorg Med Chem Lett. 2012 Jan 1;22(1):225-30.

[23] Yin B-T, Yan C-Y, Peng X-M, Zhang S-L, Rasheed S, Geng R-X, Zhou C-H. Synthesis and biological evaluation of $\alpha$-triazolyl chalcones as a new type of potential antimicrobial agents and their interaction with calf thymus DNA and human serum albumin. Eur J Med Chem. 2014 Jan;71:148-59.

[24] Suwito H, Kristanti AN, Hayati S, Dewi SR, Amalina I, Puspaningsih NNT. Antimicrobial Activities and In silico Analysis of Methoxy Amino Chalcone Derivatives. Procedia Chem. 2016;18(Mcls 2015):103-11.

[25] Gopi C, Sastry VG, Dhanaraju MD. Synthesis and spectroscopic characterisation of novel bioactive molecule of 3- ( 2-substituted ) -1H-indol-3-yl ) - 1- ( thiophen-2yl ) prop-2-en-1-one chalcone derivatives as effective anti-oxidant and anti-microbial agents. Beni-Suef Univ J Basic Appl Sci. 2016;5(3):236-43.

[26] Ahmed N, Konduru NK, Owais M. Design, synthesis and antimicrobial activities of novel ferrocenyl and organic chalcone based sulfones and bis-sulfones. Arab J Chem. 2015;

[27] Crouch LLE. The Synthesis of Organometallic Chalcones. University of Central Lancashire; 2014.

[28] Haddock BA, Jones CW. Bacterial Respiration. Bact Rev. 1977;41(1):47-99.

[29] Moodley S, Koorbanally NA, Moodley T, Ramjugernath D, Pillay M. The 3-(4,5dimethylthiazol-2-yl)-2,5-diphenyl tetrazolium bromide (MTT) assay is a rapid, cheap, screening test for the in vitro anti-tuberculous activity of chalcones. J Microbiol Methods. 2014 Sep;104:72-8.

[30] Riss TL, Moravec R, Niles AL, Benink H, Worzella TJ, Minor L. Cell Viability Assays Assay Guidance Manual. Assay Guidance Manual. 2013.

[31] Wang H, Cheng H, Wang F, Wei D, Wang X. An improved 3-(4,5-dimethylthiazol-2-yl)-2,5diphenyl tetrazolium bromide (MTT) reduction assay for evaluating the viability of Escherichia coli cells. J Microbiol Methods. 2010;82(3):330-3.

[32] Hartmann M, Berditsch M, Hawecker J, Ardakani MF, Gerthsen D, Ulrich AS. Damage of the bacterial cell envelope by antimicrobial peptides gramicidin $S$ and PGLa as revealed by transmission and scanning electron microscopy. Antimicrob Agents Chemother. 2010;54(8):3132-42.

[33] Zhao L, Zhang H, Hao T, Li S. In vitro antibacterial activities and mechanism of sugar fatty acid 
esters against five food-related bacteria. Food Chem. 2015;187:370-7.

[34] Andrews JM. Determination of minimum inhibitory concentrations. J Antimicrob Chemother. 2001 Jul 1;48(suppl 1):5-16.

[35] Medu EO. Examination of the antibacterial activities of some semi-synthetic chalconederivatives alone and in combination with polymyxin B. Robert Gordon University; 2013.

[36] Basch H, Gadebusch HH, Brunswick N. In Vitro Antimicrobial Activity of Dimethylsulfoxide. Appl Microbiol. 1968;16(12):1953-4.

[37] Hassan AS. The Antibacterial Activity of Dimethyl Sulfoxide (DMSO) with and without of Some Ligand Complexes of the Transitional Metal Ions of Ethyl Coumarin against Bacteria Isolate from Burn and Wound Infection. J Nat Sci Res. 2014;4(19):106-11.

[38] Bolla JM, Alibert-Franco S, Handzlik J, Chevalier J, Mahamoud A, Boyer G, Kiec-Kononowicz K, Pags JM. Strategies for bypassing the membrane barrier in multidrug resistant Gram-negative bacteria. FEBS Lett. 2011;585(11):1682-90.

[39] Fux CA, Shirtliff M, Stoodley P, Costerton JW. Can laboratory reference strains mirror "RealWorld" pathogenesis? Trends Microbiol. 2005;13(2):58-63.

[40] Li J, Wang G, Zhu H, Zhang M, Zheng X, Di Z, Liu X, Wang X. Antibacterial activity of large-area monolayer graphene film manipulated by charge transfer. Sci Rep. 2014;4:4359.

[41] Zengin $\mathrm{H}$, Baysal $\mathrm{AH}$. Antibacterial and antioxidant activity of essential oil terpenes against pathogenic and spoilage-forming bacteria and cell structure-activity relationships evaluated by SEM microscopy. Molecules. 2014;19(11):17773-98.

[42] Kunthalert D, Baothong S, Khetkam P, Chokchaisiri S, Suksamrarn A. A chalcone with potent inhibiting activity against biofilm formation by nontypeable haemophilus influenzae.

Microbiol Immunol. 2014;58(10):581-9.

[43] Kowalski K, Koceva-Chy A, Szczupak L, Hikisz P, Bernasińska J, Rajnisz A, Solecka J, Therrien B. Ferrocenylvinyl-flavones: Synthesis, structure, anticancer and antibacterial activity studies. J Organomet Chem. 2013;741-742(1):153-61. 

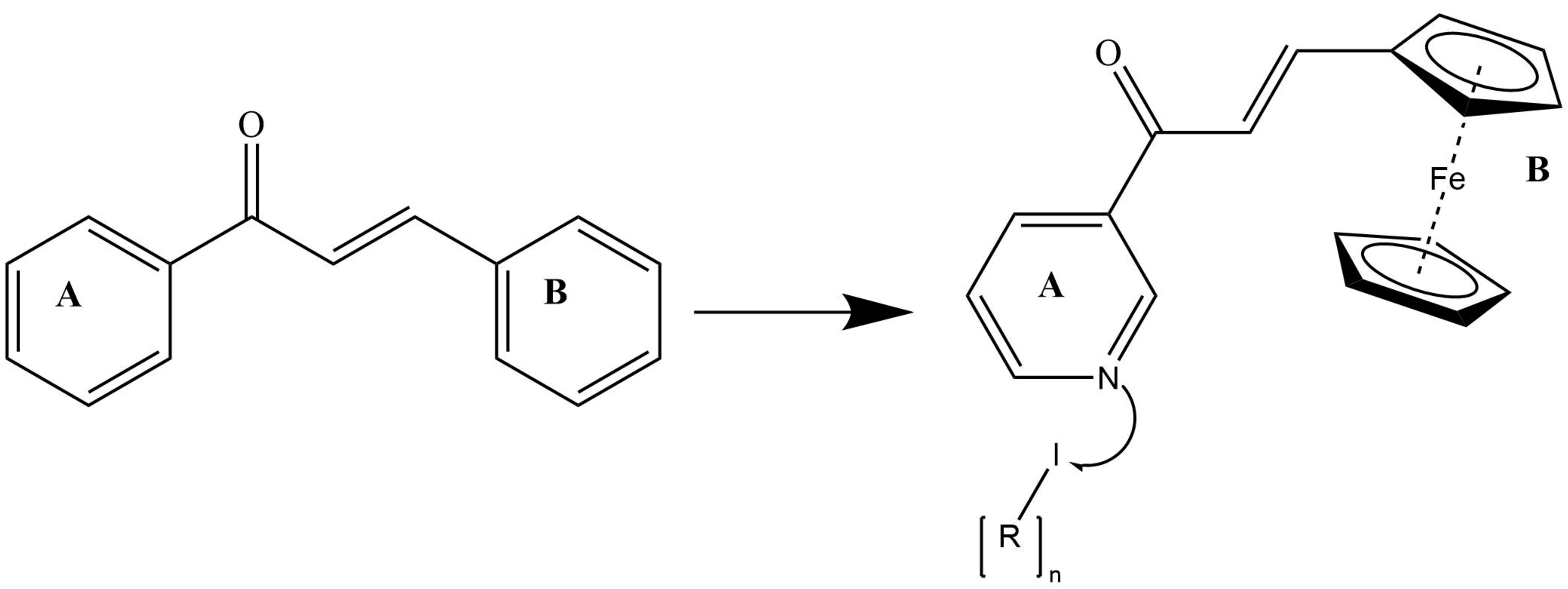

Figure 3 - Diagram of basic structure of chalcone followed by nitrogen substitution and alkyl iodide addition in ring $\mathrm{A}$ and a ferrocenyl group substitution on ring B (drawn by E. Henry, 2014). 


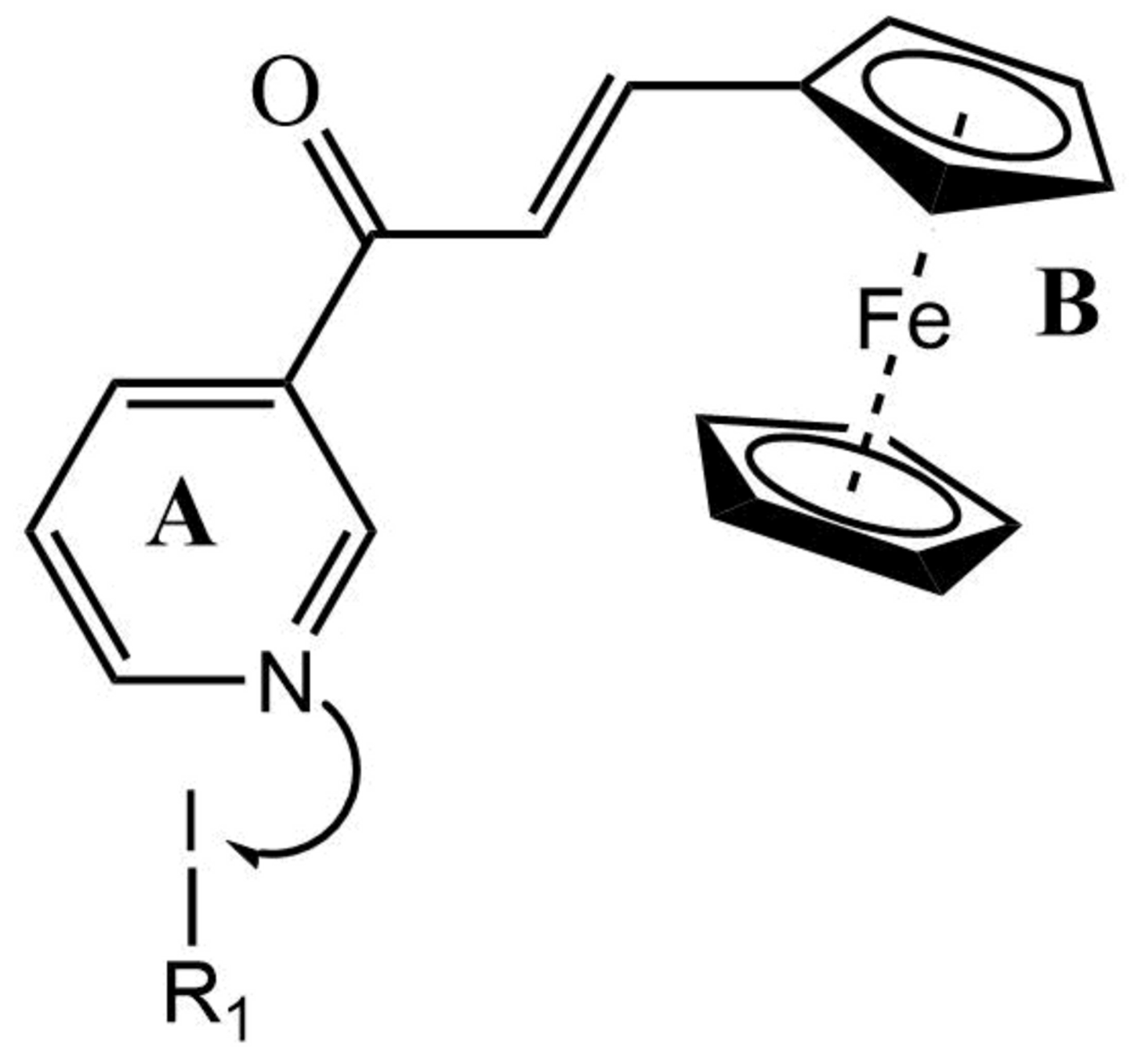

Ferrocenyl chalcone derivative

Attached R group

$-\mathrm{CH}_{3}$

$-\mathrm{C}_{2} \mathrm{H}_{5}$

$-\mathrm{C}_{3} \mathrm{H}_{7}$

$-\mathrm{C}_{4} \mathrm{H}_{9}$

$-\mathrm{C}_{5} \mathrm{H}_{11}$

$-\mathrm{C}_{6} \mathrm{H}_{13}$

$-\mathrm{C}_{7} \mathrm{H}_{15}$

$-\mathrm{C}_{8} \mathrm{H}_{17}$

$-\mathrm{C}_{9} \mathrm{H}_{19}$

$-\mathrm{C}_{10} \mathrm{H}_{21}$
Name of final compound

Methyl

Ethyl

Propyl

Butyl

Pentyl

Hexyl

Heptyl

Octyl

Nonyl

Decyl

Chart 1 - Structures of the ferrocenyl chalcones used in the current study. 
Table 1- Minimum Inhibitory Concentration values $(\mathrm{mg} / \mathrm{ml})$ of methyl to decyl ferrocenyl chalcone compounds against non-resistant and resistant lab isolates and clinical isolates. $\mathrm{RCH}=$ Royal Chesterfield Hospital; $\mathrm{IH}=$ Ian Hopkins; PEN= penicillin; ERY = erythromycin; CLI = clindamycin; MRSA = methicillin-resistant S. aureus.

\begin{tabular}{|c|c|c|c|c|c|c|c|c|c|c|}
\hline \multirow[t]{2}{*}{ Organism } & \multicolumn{10}{|c|}{ Mean $( \pm 0.000, n=6)$ MIC $(\mathrm{mg} / \mathrm{ml})$} \\
\hline & Methyl & Ethyl & Propyl & Butyl & Pentyl & Hexyl & Heptyl & Octyl & Nonyl & Decyl \\
\hline S. aureus NCIMB 8244 & 0.125 & 0.125 & 0.125 & 0.125 & 0.125 & 0.063 & 0.063 & 0.063 & 0.063 & 0.031 \\
\hline K. kristinae NCIMB 8884 & 0.125 & 0.125 & 0.125 & 0.125 & 0.125 & 0.031 & 0.008 & 0.016 & 0.016 & 0.016 \\
\hline E. faecalis NCTC 12697 & 0.125 & 0.125 & 0.125 & 0.125 & 0.125 & 0.063 & 0.063 & 0.063 & 0.063 & 0.063 \\
\hline S. aureus Fully Sens. (RCH) & - & - & - & - & - & 0.125 & 0.063 & 0.063 & 0.063 & 0.063 \\
\hline PEN-resistant S. aureus (RCH) & - & - & - & - & - & 0.063 & 0.031 & 0.063 & 0.063 & 0.063 \\
\hline PEN-, ERY-, CLI-resistant (RCH) & - & - & - & - & - & 0.063 & 0.031 & 0.063 & 0.063 & 0.063 \\
\hline MRSA (RCH) & - & - & - & - & - & 0.063 & 0.063 & 0.063 & 0.063 & 0.063 \\
\hline E. coli NCIMB 9483 & 0.125 & 0.125 & 0.125 & 0.125 & 0.125 & 0.125 & 0.125 & 0.125 & 0.125 & 0.125 \\
\hline K. pneumoniae (IH) & 0.125 & 0.125 & 0.125 & 0.125 & 0.125 & 0.125 & 0.125 & 0.125 & 0.125 & 0.125 \\
\hline Salmonella "Manchester" NCTC 7372 & 0.125 & 0.125 & 0.125 & 0.125 & 0.125 & 0.125 & 0.125 & 0.125 & 0.125 & 0.125 \\
\hline E. coli Fully Sens. (RCH) & - & - & - & - & - & 0.125 & 0.125 & 0.125 & 0.125 & 0.125 \\
\hline
\end{tabular}




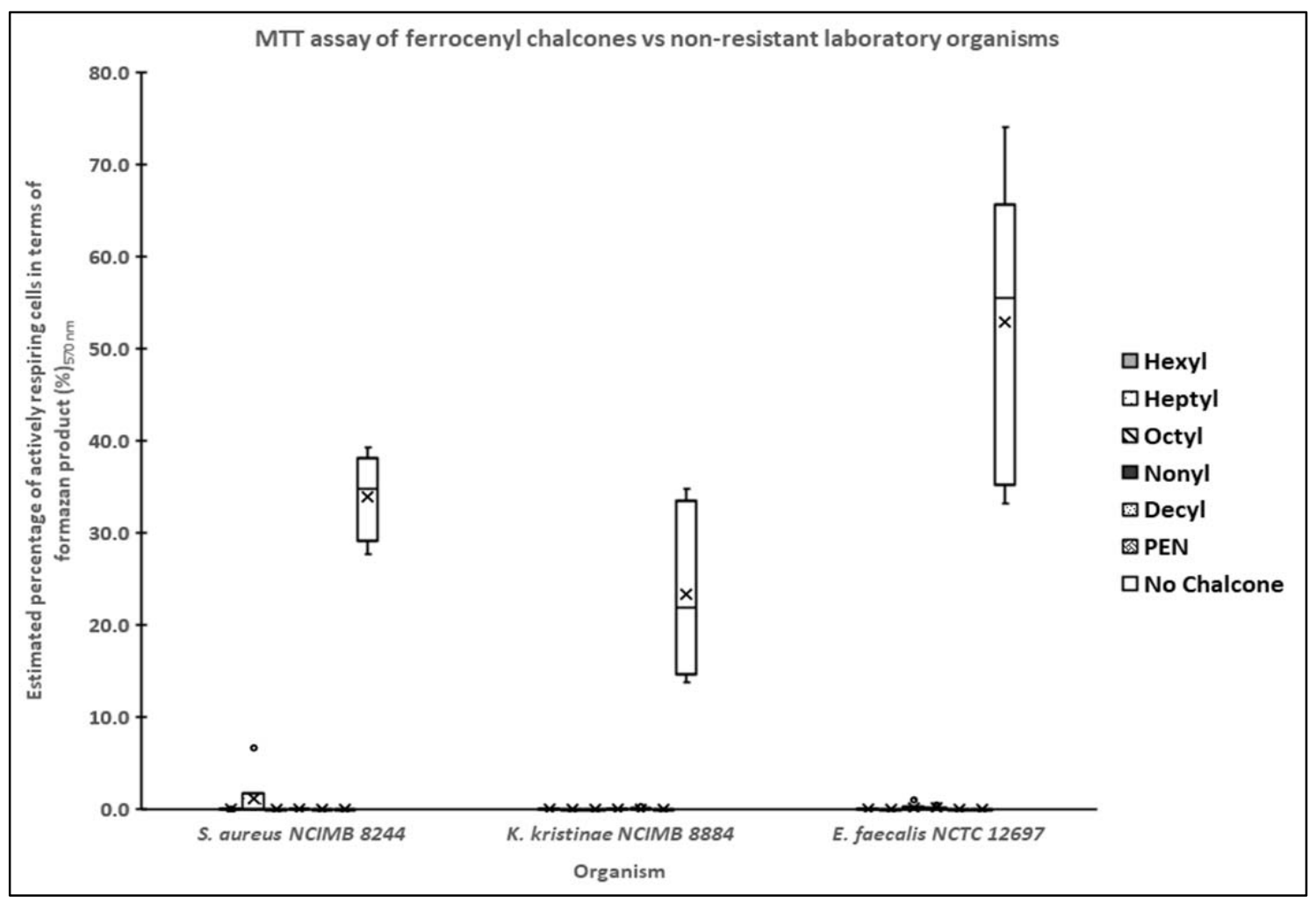

Figure 4 - Estimated percentage of actively respiring non-resistant lab bacterial cells when treated with ferrocenyl chalcone at MIC. Box plots represent the lower and upper quartiles with the medians shown as black lines. Whiskers represent the minimum and maximum percentages and each $\mathrm{X}$ represents the mean values. 


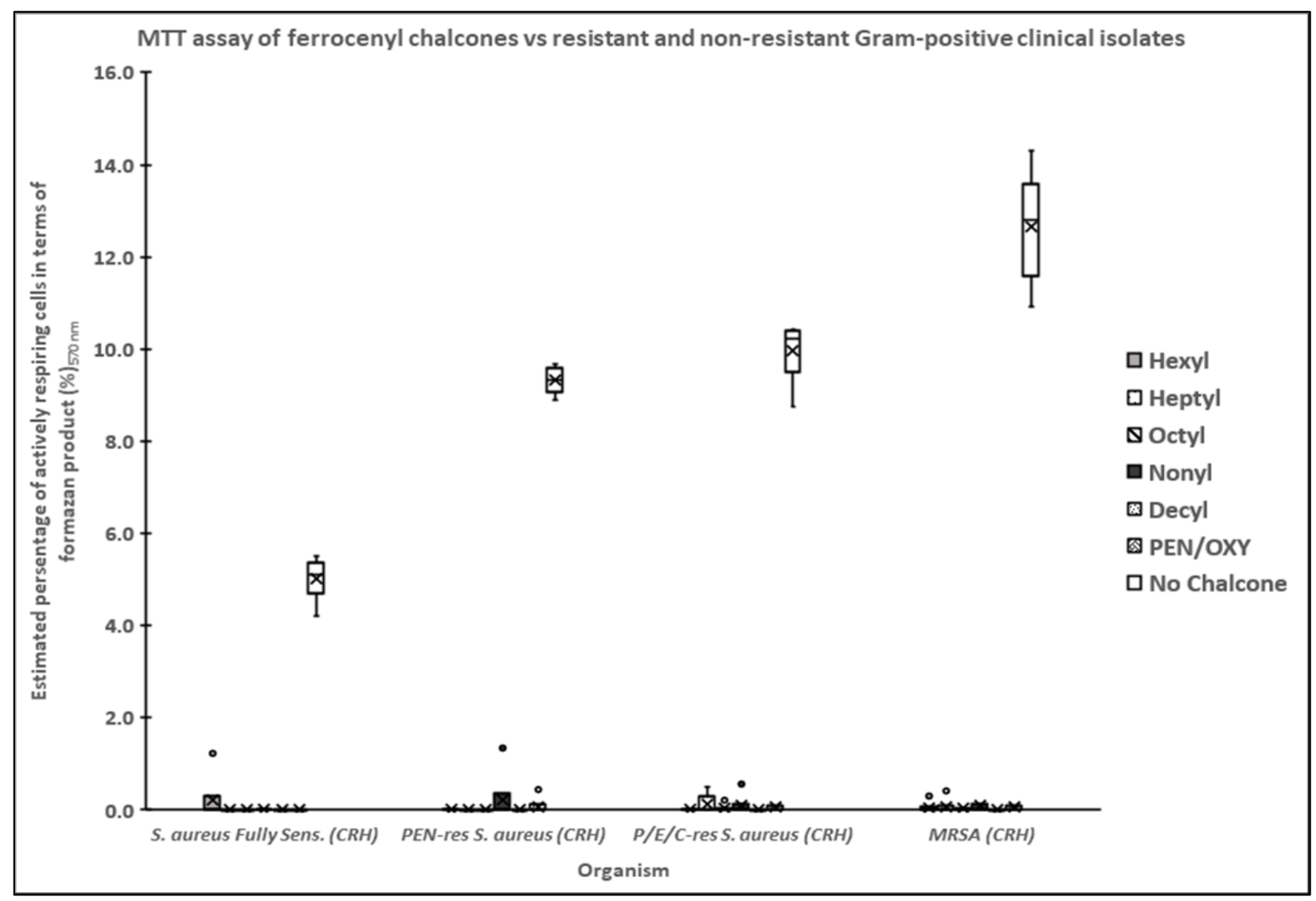

Figure 5 - Estimated percentage of actively respiring resistant and non-resistant clinically isolated bacterial cells when treated with ferrocenyl chalcone at MIC. Box plots represent the lower and upper quartiles with the medians shown as black lines. Whiskers represent the minimum and maximum percentages and each $\mathrm{X}$ represents the mean values. 

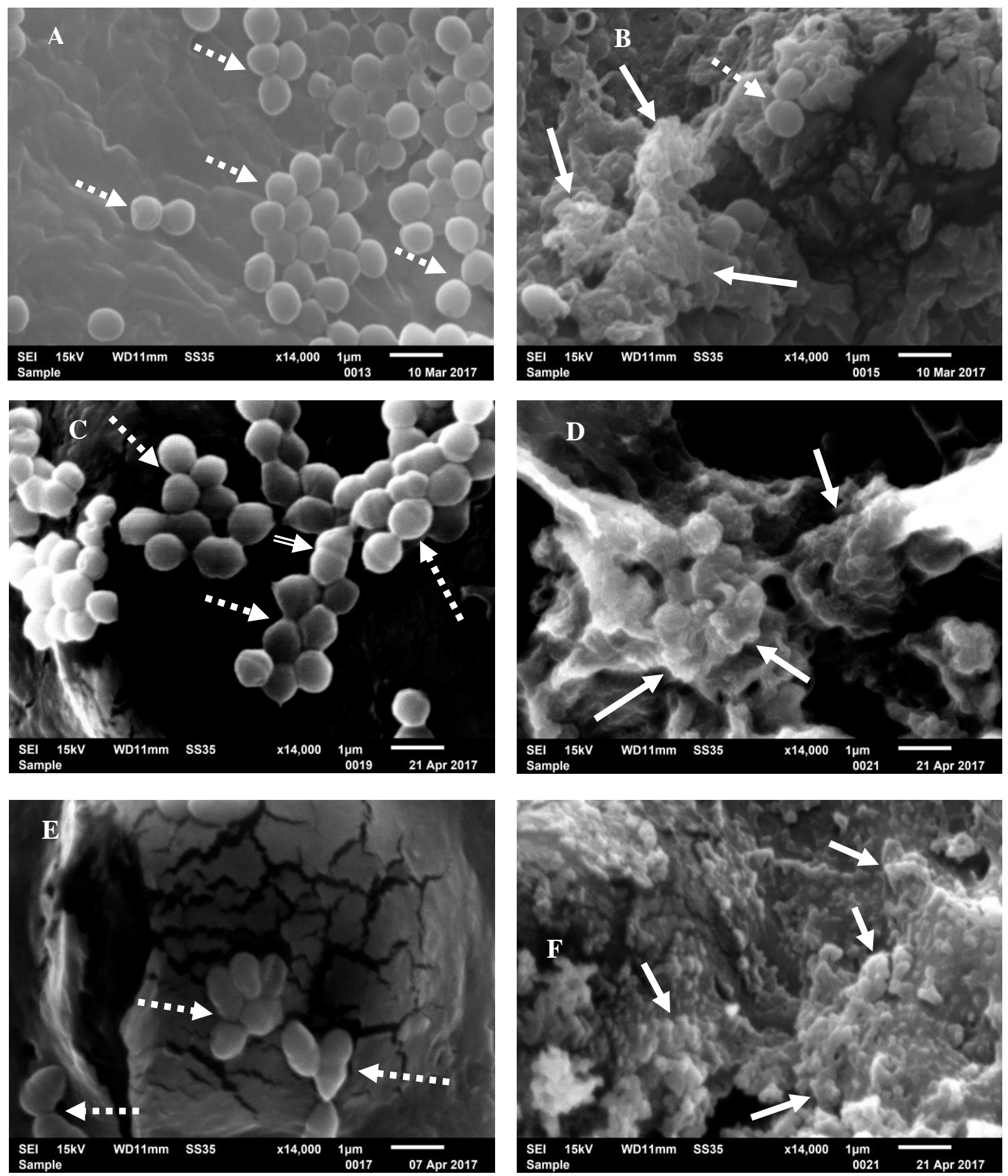

Figure 6 - SEM images: A) untreated $S$. aureus NCIMB 8244 (dotted arrows indicate some of the cells with spherical appearance); B) treated S. aureus NCIMB 8244 (dotted arrow indicates an unaffected cell and solid arrows indicate some of the fully lysed cells at MIC $0.031 \mathrm{mg} / \mathrm{ml}$ ); C) untreated K. kristinae NCIMB 8244 (dotted arrows indicate some of the cells with spherical appearance and double-lined arrow indicates a dividing cell); D) treated K. kristinae NCIMB 8884 (solid arrows indicate some of the fully lysed cells at MIC $0.016 \mathrm{mg} / \mathrm{ml}$ ); E) untreated E. faecalis NCTC 12697 (dotted arrows indicate some of the cells with normal appearance); F) treated $E$. faecalis NCTC 12697 (solid arrows indicate some of the severely damaged cells at MIC 0.063 $\mathrm{mg} / \mathrm{ml})$. 